\title{
ORGANOCHLORINE CONTAMINATION IN SEDIMENTS COLLECTED FROM A RURAL-, URBAN- AND INDUSTRIAL- IMPACTED AQUATIC SYSTEM (DANUBE, SERBIA)
}

\author{
Maja Brborić*, Jelena Radonić*, Mirjana Vojinović Miloradov", Sabolč Pap ${ }^{* *}$, \\ Maja Turk Sekulić* \\ * University of Novi Sad, Faculty of Technical Sciences, Novi Sad, Serbia \\ ** University of the Highlands and Islands, North Highland College, Environmental Research Institute, \\ Thurso, United Kingdom
}

corresponding author: Maja Brborić, e-mail: majabrboric@uns.ac.rs

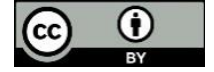

This work is licensed under a

Creative Commons Attribution 4.0

International License
Original scientific paper

Received: October $14^{\text {th }}, 2019$

Accepted: December 10 $0^{\text {th }}, 2019$

HAE-1924

https://doi.org/10.33765/thate.10.2.3

\begin{abstract}
The spatial distribution of various organochlorinated compounds (PCBs and OCPs (DDTs, HCB, and $\mathrm{HCHs}$ )) were investigated in sediments of Serbia's stretch of the Danube River. The obtained concentrations appeared to be relatively low in comparison with other river sediments worldwide. The results demonstrated a wide range of concentrations $(\mu \mathrm{g} / \mathrm{kg}$ dry weight) with the following decreasing order: $\Sigma_{6}$ DDTs $(0.70-16.65)>\Sigma_{7}$ PCBs $(0.25-3.54)>\Sigma_{5} \mathrm{HCH}(0.04-2.28)>\mathrm{HCB}$ (0.06 - 0.62), with a dominance of o,p' -DDT. Relatively higher $\Sigma$ DDT concentrations and high DDT/DDE + DDD ratios in two sampling locations near the industrial cities indicates a current DDT usage, probably linked to public health concerns. Compositional analyses indicated that hexaand hepta-PCBs were dominant for PCBs. Our results indicated that the contamination with PCBs came from nonpoint deposition, such as atmospheric contribution and surface runoff, for lightly chlorinated congeners and point source deposition, such as the industrial sources along river flow, for highly chlorinated congeners, whereas OCPs originate mainly from old residues and new usage of pesticides in agriculture and aquaculture. These results contribute to the sparse regional database for organochlorinated compounds in the Danube basin.
\end{abstract}

Keywords: Danube sediment, $P C B s, D D T s, H C B, H C H s$

\section{INTRODUCTION}

In recent years, the accelerated accrual in the human population and industrialization has led to an increase in the waste and emission of contaminants in all environmental compartments. Among all types of contaminants, the lipophilic chemical species raise major concern due to their ecological and socioeconomic implications (loss of biodiversity, contamination of food, degradation of habitat, deprivation of 
livelihood) as well as their impact on human health [1].

Polychlorinated biphenyls (PCBs) and chlorinated pesticides (e.g., DDTs, HCB, HCHs, etc.), are an important group of persistent organic compounds (POPs) included in the Stockholm Convention: they are globally distributed and their properties cause worldwide concern as toxic environmental contaminants [2,3] in a warming world. Organochlorinated compounds have been widely used, with both industrial and agricultural sources contributing significant amounts to the environment through leakage, disposal and evaporation. Although production and use of these pollutants are prohibited, human activities may still release PCBs and OCPs into the environment, such as the maintenance of electrical equipment, re-use of fluids, demolition of buildings, recycling operations, incineration of industrial and domestic products, inadequate waste disposal and illegal discharges. In the aquatic ecosystems, chlorinated compounds cause great concern due to their persistent nature, hydrophobic character, low water solubility, long-range transport, bioaccumulation, toxicity as well as carcinogenicity [4]. As a result, sediments are usually regarded as the ultimate sink for many classes of anthropogenic contaminants to the environment and are one of the best media for the long-term monitoring of many POPs [5]. As sediments may receive these pollutant discharges, trapping and accumulating contaminants over time, this compartment is widely recognized as important natural reservoir and large environmental sink and is used for evaluating the health of aquatic ecosystem [6].

In view of the above, the present study provides valuable information on concentration levels and spatial distribution of polychlorinated biphenyls (PCBs) and organochlorine pesticides (DDTs, HCB, and $\mathrm{HCH})$ in surface sediments to ascertain the contamination status of the Serbia's stretch of Danube river.

\section{EXPERIMENTAL}

\section{Sediment sampling}

The sampling was performed in October 2012. For this investigation, 10 samples of bottom sediment from different sites of Danube River through Serbia (Apatin - D1 (1401 km), Labudnjača - D2 (1367 km), Neštin - D3 (1264 km), Begeč - D4 (1275 km), Ratno Ostrvo - D5 (1257 km), Šangaj - D6 (1250 km), Knićanin - D7 (1214 km), Belegiš - D8 $(1199 \mathrm{~km})$, Ritopek - D9 (1141 km), Dubravica - D10 (1103 km)) were collected using a grab sampler (Figure 1). Samples were taken to the laboratory in an ice cooler, where they were weighed and sealed to avoid contamination. All sediment samples were analysed in the laboratory of Research Centre for Toxic Compounds in the Environment RECETOX (Brno, Czech Republic) two days later. Before being analysed, wet sediment samples were sieved through $2 \mathrm{~mm}$ sieve to remove leaves, stones and roots. The sediments were well homogenized and subsamples were taken in $150 \mathrm{ml}$ glass jar for freeze-drying.

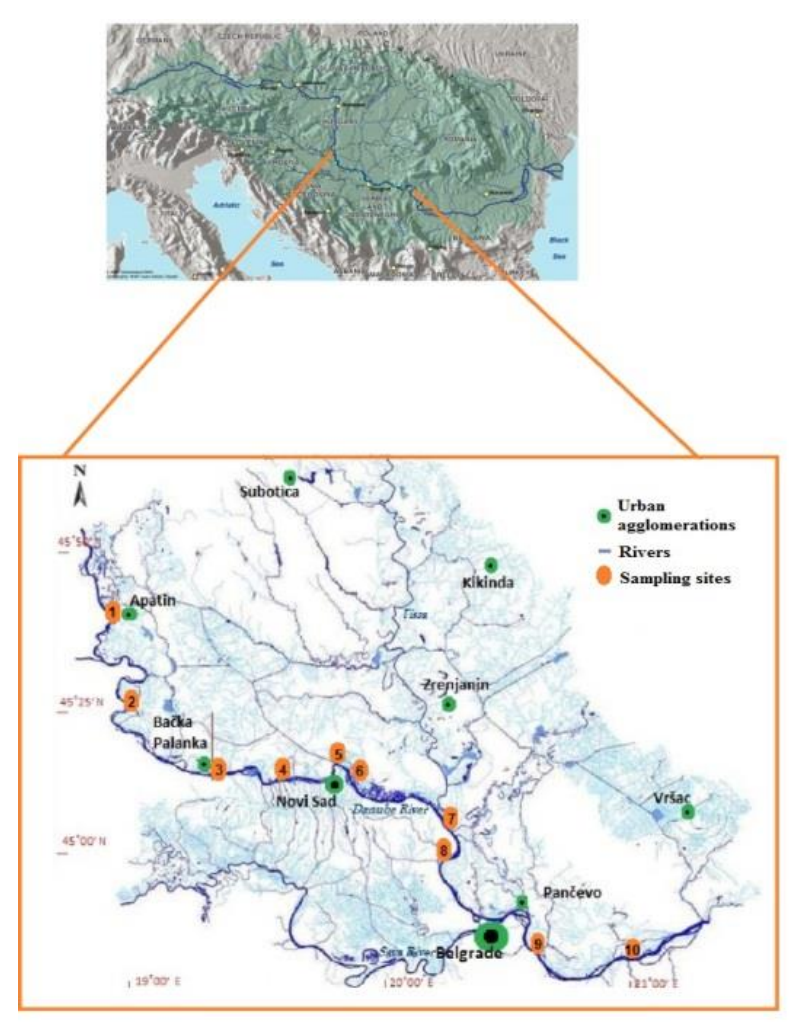

Figure 1. Danube River sampling sites 


\section{Sediment analysis}

About $7-8 \mathrm{~g}$ of the freeze-dried sediment samples were extracted with dichloromethane in a Büchi System B-811 automatic extractor. One laboratory blank and one reference material were analysed with each set of ten samples. Surrogate recovery standards (PCB 30, PCB 185 in amount of $10 \mathrm{ng}$ for PCBs analysis) were spiked in each sediment prior to extraction. After extraction, the sample volume was reduced to about $1-1.5 \mathrm{ml}$ and transferred to hexane using azeotrope principle on Kuderna-Danish evaporation unit resulting in the end with $1 \mathrm{ml}$ of extract in hexane. For OCPs and PCBs clean up and analysis, the extract went through $8 \mathrm{~g}$ of activated silica gel modified with sulphuric acid column and eluted with $30 \mathrm{ml}$ hexane: dichloromethane. The volume of the extracts was again reduced and transferred to hexane using KudernaDanish evaporation unit to about $1 \mathrm{ml}$ in hexane. The extracts were further reduced under soft nitrogen flow to about $0.5 \mathrm{ml}$. The extract was quantitatively transferred to GCMS vial and the final volume was brought to 1 ml. For quantification of OCPs and PCBs, 10 ng of PCB 121 was added as syringe internal standard. The extract was quantitatively transferred to GC-MS vial and the volume was reduced to about $0.1 \mathrm{ml}$.

Samples were analysed using a GC-MS/MS (GC 7890/MS-MS Triple Quadrupole 7000B; Agilent) supplied with a SGE-HT8 (60 m x $0,25 \mathrm{~mm} \times 0,25 \mathrm{um}$ ) column for PCBs and OCPs: PCB 28, PCB 52, PCB 101, PCB 118, PCB 153, PCB 138, PCB 180 and OCPs : $\alpha-$ hexachlorocyclohexane $(\mathrm{HCH}), \beta-\mathrm{HCH}, \gamma-$ $\mathrm{HCH}, \quad \delta$-HCH, 1.1-dichloro-2.2-bis ( $p$ chlorophenyl) ethylene ( $p, p^{\prime}$-DDE), 1.1dichloro-2.2-bis ( $p$-chlorophenyl) ethan ( $p, p^{\prime}$ DDD), 1.1.1-trichloro-2.2-bis ( $p$-chlorophenyl) ethan ( $\left.p, p^{\prime}-\mathrm{DDT}\right), o, p^{\prime}-\mathrm{DDE}, o, p^{\prime}-\mathrm{DDD}, o, p^{\prime}$ DDE, hexachlorobenzene (HCB), and pentachlorobenzene (PeCB). PCB 121 were used as internal standards for polychlorinated biphenyl (PCB)/organochlorine pesticide (OCP) analyses, respectively.

\section{RESULTS AND DISCUSSION}

The spatial trend of polychlorinated biphenyls in the collected samples of sediment within the research at 10 sampling sites is presented in Figure 2. The highest concentration levels of PCBs were detected in the areas of the most developed industrial centers in AP Vojvodina near Bačka Palanka city (Neštin: $3.54 \mu \mathrm{g} / \mathrm{kg}$ dry weight (d.w.)) and Pančevo (Ritopek: 3.27 $\mu \mathrm{g} / \mathrm{kg}$ d.w.), which is the consequence of today's active industrial activities amplified by the historical pollution of industrial waste released into the environment of such past, but also possible accumulation of these toxic pollutants in the Danube sediment after NATO bombing in 1999. The PCB values obtained in this study were lower compared to the Joint Danube Survey 1 and 2 [7] expedition, which examined the influence of organic pollutants at the Serbian part of the Danube during 2007 and 2013. At all analysed samples, concentration levels of total PCB congener values were below the remediation values prescribed by the Regulation on emission limit for pollutants in surface and ground waters and sediment and deadlines for their reaching ("Official Gazette of the RS", No. 50/2012) of the Republic of Serbia.

Figure 3 shows the values of PCB congeners grouped by the number of substituted $\mathrm{Cl}$ atoms at the benzene ring. The most commonly used PCB congeners in sediment samples were with six and seven chlorine atoms in samples collected at three sites around Novi Sad (77.2 $\%, 81.9 \%$ and $84.3 \%$ for Begeč, Ratno ostrvo and Šangaj, respectively of the total value of analysed PCBs) and at the site near Pančevo (73.1\% for Ritopek). The presence of PCB congeners chlorinated with a large number of $\mathrm{Cl}$ atoms $(5-7 \mathrm{Cl})$ indicates their long presence, and therefore their significant negative impact on the environment.

The concentration of total OCPs (PeCB, HCH, DDE, DDD, and DDT) in sediment samples ranged from $0.82 \mu \mathrm{g} / \mathrm{kg}$ (Belegiš, D8) to 17.20 $\mu \mathrm{g} / \mathrm{kg}$ d.w. (Ritopek, D9) (mean value: $6.55 \pm$ $5.14 \mu \mathrm{g} / \mathrm{kg}$ d.w.) (Figure 4). The mean concentration of $\mathrm{PeCB}$ and $\mathrm{HCH}$ 
concentrations were $0.30 \pm 0.23 \mu \mathrm{g} / \mathrm{kg}$ and $1.17 \pm 0.89 \mu \mathrm{g} / \mathrm{kg}$ d.w., respectively, with similar spatial distribution pattern. At all sites, DDT and its metabolites DDE and DDD were quantified and occupied from $44.73 \%$ (D4) to $96.79 \%$ (D9) of the total detected OCPs. The mean concentrations of $\Sigma D D E, \Sigma D D D$, and $\Sigma$ DDT (sum of o,p 'and p,p') ranged from 0.25 to $4.76,0.31$ to 2.86 and 0.16 to $9.84 \mu \mathrm{g} / \mathrm{kg}$ d.w., respectively, while the total values of ¿DDT ranged from 0.70 (D8) to 16.65 (D9) $\mu \mathrm{g} / \mathrm{kg}$ d.w. with a mean value of $5.08 \mu \mathrm{g} / \mathrm{kg}$ d.w. and a median of $3.00 \mu \mathrm{g} / \mathrm{kg}$ d.w. Comparing the quantified concentration values obtained in this study with other studies examining aquatic sediment, it can be found that the detected $\Sigma$ OCP values are significantly lower than the sediment concentrations in Gomti River, India [8] while the obtained values were similar with studies conducted on the Danube River, Romania [9]. By comparing the obtained values of the concentration of DDT and its metabolites with the values prescribed by the Serbian regulation, it can be concluded that at the site Ritopek the values of इDDT, $\Sigma$ DDE and $\Sigma$ DDD exceed a considerable degree of maximum permissible concentrations, while the values obtained for SDDT total do not indicate that remediation measures should be performed in either of the examined sites.

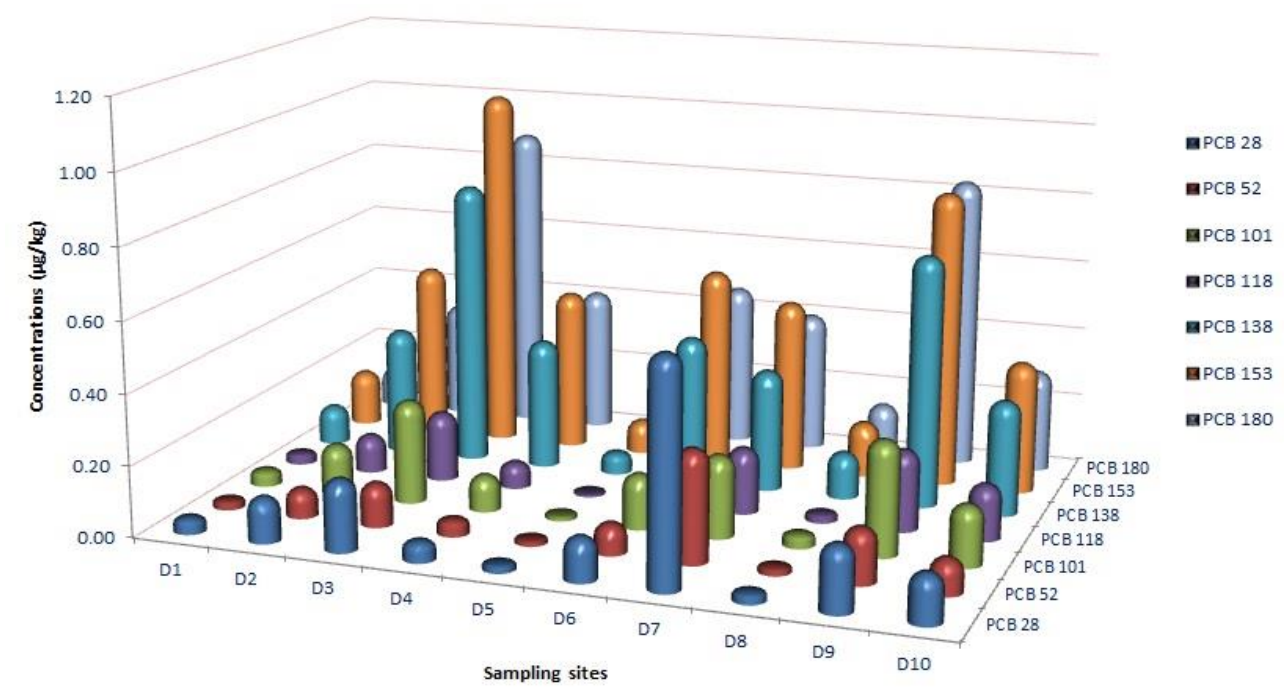

Figure 2. Spatial distribution of PCBs in sediment samples

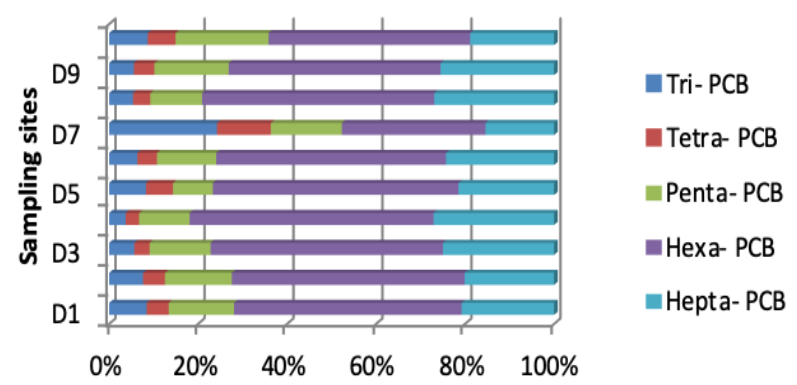

Figure 3. Composition of PCBs in sediment samples according to the number of substituted chlorine atoms 


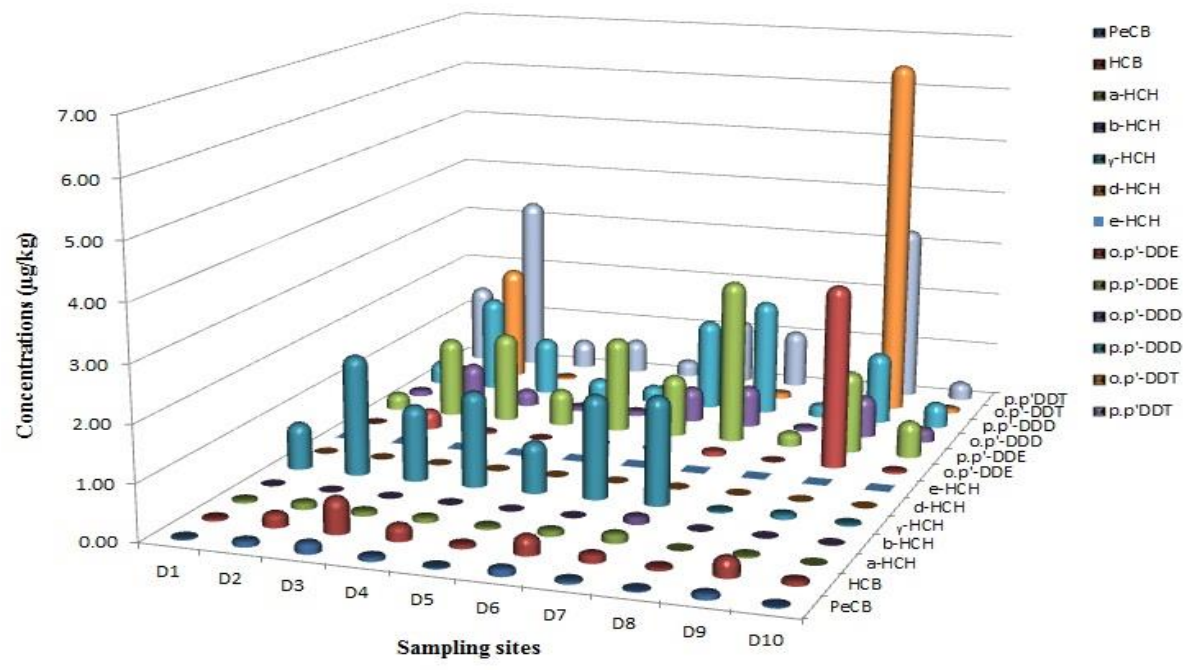

Figure 4. Spatial distribution of total OCPs in sediment samples

Because of the low proportions of DDE and DDD in technical DDT, the ratio DDT/(DDE+DDD) for all sediment samples can be monitored. The values $<1.0$ generally indicate the use in the past, whereas the ratio $>$ 1.0 indicates the current usage of DDT. The DDT/(DDE+DDD) ratio for analysed samples of the Danube river near Apatin, Labudnjača, and Ritopek indicates that DDT in our country continues to be used although its use was prohibited at the end of the 1980s. At other sites, this ratio is $<1$ and points to pollution caused in the past.

The total organic carbon (TOC) content in sediment samples ranged from 0.3 to $1.3 \%$, indicating a significant variation in spatial distribution, but without a clear trend. In this study, a correlation analysis was performed to obtain information about the interactions between PCBs, OCPs, and TOC. There was a positive, significant linear correlation between the sum of the concentration of PCBs and TOC sediment contents in the Danube River ( $r$ $=0.93 ; \mathrm{p}<0.01)$, but a significant correlation was also observed between the content of organic matter and the individual values of PCB congeners detected in the samples sediment and ranged from $r=0.71$ (for $\mathrm{PCB}$ 28) to $r=9.52$ (for PCB 118). The values obtained are much higher than the correlation coefficients obtained in other studies $[10,11]$. The values of TOC were significantly correlated with $\Sigma$ DDE concentrations $(\mathrm{r}=$
$0.68 ; \mathrm{p}<0.05)$ and $\operatorname{\Sigma DDD}(\mathrm{r}=0.66 ; \mathrm{p}<0.05)$ and to a lesser extent with $\Sigma$ DDT $(\mathrm{r}=0.34 ; \mathrm{p}<$ $0.05)$. Significant correlations between $\Sigma D D T$ and $\Sigma$ DDE concentrations $(r=0.77 ; p<0.05)$ were found. These results suggest that organic matter in the sediment can play a more important role in the levels of PCBs and OCPs. PCBs are highly lipophilic and TOC content in sediment is a major factor in controlling the biological availability of PCBs. Sediment with lower TOC generally results in a higher percentage of PCBs and OCPs partitioned in interstitial water and thus have the ability to be absorbed more easily in benthic organisms.

\section{CONCLUSION}

The research under this study was based on the monitoring carried out in 2012 to determine the concentration levels and spatial distribution of polychlorinated biphenyls and organochlorine pesticides, specific lipophilic persistent organic pollutants in the complex aquatic sedimentation system of the river Danube on sites with significant anthropogenic influence in the Republic of Serbia. Based on the overall analysis of the obtained results, it can be established that the specificity of the spatial distribution of individual congeners at selected sites may be related to agricultural activities, uncontrolled wastewater discharge, 
uncontrolled burning, but also destruction of the facility during the NATO bombing in 1999, especially near the town of Pančevo, the confirmation of which requires further research Also, it can be concluded that the Danube riverbank flow at the territory of Serbia still has significant potential pollution sources of aquatic systems with organochlorine pesticides, which is necessary to detect more extensive monitoring and prevent further use by adequate controls of pesticides imported and produced today in our country, thus diminishing the extremely negative ecotoxicological effects currently present in the aquatic system. Within the framework of such a systematized research process it would be necessary to include more media (biotic and abiotic) in the analysis as well as more specific points.

\section{REFERENCES}

[1] B.O. Botwe, P. Kelderman, E. Nyarko, P.N.L. Lens, Assessment of DDT, HCH and PAH contamination and associated ecotoxicological risks in surface sediments of coastal Tema Harbour (Ghana), Marine Pollution Bulletin 115(2017) 1-2, 480-488.

[2] T.C. Nguyen, P. Loganathan, T.V. Nguyen, S. Vigneswaran, J. Kandasamy, D. Slee, G. Stevenson, R. Naidu, Polycyclic aromatic hydrocarbons in road deposited sediments, water sediments, and soils in Sydney, Australia: Comparisons of concentration distribution, sources and potential toxicity, Ecotoxicology and Environmental Safety 104(2014), 339348.

[3] I. Tongo, L. Ezemonye, K. Akpeh, Levels, distribution and characterization of polycyclic aromatic hydrocarbons (PAHs) in Ovia river, Southern Nigeria, Journal of Environmental Chemical Engineering 5(2017) 1, 504-512.

[4] E. Nyarko, B.O. Botwe, E. Klubi, Polycyclic aromatic hydrocarbons
(PAHs) levels in two commercially important fish species from the coastal waters of Ghana and their carcinogenic health risks, West African Journal of Applied Ecology 19(2011) 1, 53-66.

[5] I. Hussain, J.H. Syed, A. Kamal, M. Iqbal, S.A.M.A.S Eqani, C.W. Bong, M.M. Taqi, T.G. Reichenauer, G. Zhang, R.N. Malik, The relative abundance and seasonal distribution correspond with the sources of polycyclic aromatic hydrocarbons (PAHs) in the surface sediments of Chenab River, Pakistan, Environmental Monitoring and Assessment 188(2016), Article number: 378

[6] C.C. Martins, M.C. Bícego, R.C.L. Figueira, J.L.F. Angelli, T. Combi, W.C. Gallice, A.V. Mansur, E. Nardes, M.L. Rocha, E. Wisnieski, L.M.M. Ceschim, A.P. Ribeiro, Multi-molecular markers and metals as tracers of organic matter inputs and contamination status from an Environmental Protection Area in the SW Atlantic (Laranjeiras Bay, Brazil), Science of The Total Environment 417418(2012), 158-168.

[7] I. Liška, F. Wagner, M. Sengl, K. Deutsch, J. Slobodník, Joint Danube Survey 3 - A Comprehensive Analysis of Danube Water Quality, ICPDRInternational Commission for the Protection of the Danube River, Vienna Austria, 2015.

https://www.icpdr.org/main/sites/default/ files/nodes/documents/jds3 final_scienti fic_report_2.pdf Accessed: November 26, 2019.

[8] A. Malik, P. Ojha, K.P. Singh, Levels and distribution of persistent organochlorine pesticide residues in water and sediments of Gomti River (India) - a tributary of the Ganges River, Environmental Monitoring and Assessment 148(2009) 1-4, 421-435.

[9] A. Covaci, A. Gheorghe, O. Hule, P. Schepens, Levels and distribution of organochlorine polychlorinated biphenyls and polybrominated diphenyl ethers in sediments and biota from the Danube 
Delta, Romania, Environmental Pollution 140(2006) 1, 136-149.

[10] C.H. Vane, I. Harrison, A.W. Kim, Polycyclic aromatic hydrocarbons (PAHs) and polychlorinated biphenyls (PCBs) in sediments from the Mersey Estuary, UK, Science of The Total Environment 374(2007) 1, 112-126.

[11] K. Hilscherová, L. Dusek, T. Š́dlová, V. Jálová, P. Čupr, J.P. Giesy, S. Nehyba, J. Jarkovský, J. Klánová, I. Holoubek, Seasonally and regionally determined indication potential of bioassays in contaminated river sediments, Environmental Toxicology and Chemistry 29(2010) 3, 522-534.

\section{Acknowledgements}

This research was supported by the Ministry of

Education, Science and Technological Development, Republic of Serbia (III46009). 